\title{
Cellular and Humoral Immunity in the Pathogenesis of Recurrent Herpes Viral Infections in Patients with Lymphoma
}

\author{
A. M. Arvin, R. B. Pollard, L. E. Rasmussen, and T. C. Merigan, Department \\ of Medicine, Division of Infectious Diseases, Stanford University School of \\ Medicine, Stanford, California 94305
}

A B S T R A C T 86 patients with lymphoma were evaluated prospectively for clinical and laboratory evidence of recurrent varicella-zoster, herpes simplex, and cytomegalovirus infections during the first 16 mo of treatment. Cellular immunity to the viral antigens was measured by in vitro lymphocyte transformation and interferon production. Antibody titers and nonspecific measures of cellular immunity, including $\mathrm{T}$-cell quantitation and transformation to phytohemagglutinin, were also assessed. The patients treated with radiation and chemotherapy had the highest incidence of reactivation of each of the viruses (15-19\%). Greater susceptibility to herpes viral reactivation in these patients correlated with suppression of cell-mediated immunity to the specific virus. In individual patients, suppression of cellular immunity to the specific herpes viral antigen preceded each episode of reactivation, but recurrent infection did not occur in all patients with diminished specific lymphocyte transformation. Absence of the response appears to be a necessary but not a sufficient condition for the recrudescence of latent infection. Better preservation of cellular immunity to herpes simplex antigen during treatment was associated with infrequent reactivation of herpes simplex. In 25 patients with acute herpes zoster, uncomplicated recovery from the infection was accompanied by the development of lymphocyte transformation and interferon production to varicella-zoster antigen. Quantitation of T-cell numbers and phytohemagglutinin transformation did not correlate with the presence of viral cellular immunity in treated patients. Responses returned while T-cell numbers were low, and the

The Abstract was presented at the Fourth Herpes Virus Meeting, Cold Spring Harbor, N. Y.

Dr. Pollard's present address is Division of Infectious Diseases, University of Texas Medical Branch, Galveston, Texas.

Received for publication 2 October 1979 and in revised form 14 December 1.979. recovery of phytohemagglutinin transformation often preceded recovery of the responses to viral antigens. Although some patients had deficiencies in viral cellular immunity at diagnosis, the duration of the suppression of specific antiviral responses resulting from treatment appears to be the most important factor predisposing to the recurrence of herpes infections in lymphoma patients.

\section{INTRODUCTION}

The immunosuppressive therapy that is required to treat malignancy or to maintain transplanted organs is associated with the reactivation of latent herpes viral infections (1-5). The reactivation of varicella-zoster, herpes simplex, or cytomegalovirus can cause significant morbidity and mortality in immunocompromised patients despite the fact that the infection is recurrent rather than primary. The suppression of cellular immunity has been implicated in the pathogenesis of reactivation because recurrent herpes infections occur in patients with antibody to the specific herpes virus. Cellular immunity to varicella-zoster (VZ), ${ }^{1}$ herpes simplex (HSV), and cytomegalovirus (CMV) can be demonstrated in normal individuals who have had primary infection with these viruses using assays of in vitro lymphocyte transformation and interferon production (6-8). Lymphocyte transformation to the viral antigens is primarily a $\mathrm{T}$-cell response. Interferon is produced primarily by B cells in this assay $(9,10)$.

Patients being treated for Hodgkin's disease and nonHodgkin's lymphoma are subject to recurrent herpes viral infections, especially herpes zoster (3). The purpose of this study was to determine whether deficiencies in cellular immunity to specific herpes viral antigens could be related to episodes of viral reactiva-

\footnotetext{
${ }^{1}$ Abbreviations used in this paper: CMV, cytomegalovirus; HSV, herpes simplex; PHA, phytohemagglutinin; SI, stimulation index; VZ, varicella zoster.
} 
tion in patients with lymphoma. Lymphocyte transformation and interferon production to VZ, HSV, and CMV antigens were evaluated prospectively in 86 lymphoma patients from the time of diagnosis through the first 16 mo of treatment. The cellular immune response to viral antigens was correlated with antibody titers, with lymphocyte transformation to phytohemagglutinin (PHA), and with the quantitation of T cells to ascertain whether deficiencies in viral cellular immunity were more predictive of recurrent herpes virus infection than assays of humoral immunity or nonspecific cellular immunity.

\section{METHODS}

Patient population. The patients participating in this study were referred to Drs. Henry Kaplan and Saul Rosenberg at Stanford University Medical Center for the diagnosis and treatment of Hodgkin's disease or of non-Hodgkin's lymphoma. The patients were staged according to the Ann Arbor International Classification, with most patients undergoing a staging laparotomy with splenectomy. Cellular and humoral immunity to VZ, HSV, and CMV were evaluated in 128 patients at the time of diagnosis. 86 patients were treated at Stanford (Table I) according to defined protocols for Hodgkin's disease and non-Hodgkin's lymphoma. Treatment for Hodgkin's disease included involved field, extended field, or total nodal radiation. Patients given radiation and chemotherapy received either nitrogen mustard, vincristine, procarbazine and prednisone, or procarbazine, alkeran, and velban. NonHodgkin's lymphoma patients received involved field or mantle/whole abdomen/pelvic radiation. Patients treated with radiation and chemotherapy were given either cytoxan, vincristine, and prednisone, or adriamycin, cytosine arabinoside, and thioguanine, or cytoxan, adriamycin, vincristine, and prednisone. Some non-Hodgkin's lymphoma patients were given chemotherapy only with either chlorambucil or cyclophosphamide. None of the patients with Hodgkin's disease received chemotherapy only.

Clinical infection. A history of prior HSV and herpes zoster infections was obtained at the time patients were enrolled in the study. The symptoms of HSV and herpes zoster were reviewed with the patients and they were asked to note recurrences of $\mathrm{HSV}$ and to notify the physician of symptoms of herpes zoster. The patients were interviewed at the follow-up intervals regarding the occurrence of clinical HSV or herpes zoster during the previous 4-mo period.
Cell-mediated immunity to herpes viral antigens. The methods used in the preparation of $\mathrm{VZ}, \mathrm{HSV}$, and CMV antigens have been described (6-8). The lymphocyte transformation and interferon production assays were performed by incubating Ficoll-Hypaque-separated (Pharmacia Fine Chemicals, Div. of Pharmacia Inc., Piscataway, N. J.; Winthrop Laboratories, New York) peripheral blood mononuclear cells in $30 \%$ heat-inactivated human serum with viral antigen or with PHA for $5 \mathrm{~d}$ in a microtiter culture plate (6). Lymphocyte transformation was detected by measuring tritiated thymidine incorporation in antigen-stimulated wells $\left({ }^{3} \mathrm{H}\right.$ antigen) compared with control wells $\left({ }^{3} \mathrm{H}\right.$ control). The results are expressed as a stimulation index $\left({ }^{3} \mathrm{H}\right.$ antigen divided by ${ }^{3} \mathrm{H}$ control). A stimulation index of at least threefold was considered a positive response because previous studies of at least 40 normal seropositive subjects have shown that immune individuals respond with stimulation index $(\mathrm{SI})>3.0$ to each of the antigens used (6-8). The SI was used to analyze the data from lymphoma patients because thymidine incorporation by lymphocytes incubated with control antigen showed no significant change with treatment. Incorporations $( \pm \mathrm{SE})$ in the control wells at each follow-up interval for patients given radiation and chemotherapy were $274 \pm 53.51$, $203 \pm 42.25$, and $183 \pm 56.20$; for patients given radiation only, the values were $343 \pm 87.98,318 \pm 50.71$, and $226 \pm 51.09$; for those given chemotherapy only, the values were $339 \pm 53.08$, $409 \pm 135.63$, and $229 \pm 49.42$. Interferon production is measured by assaying the supernates from antigen-stimulated wells in a microtiter interferon assay using vesicular stomatitis virus as the challenge virus (6-8). The cellular immune responses were reproducible in 12 of 13 patients evaluated twice before treatment.

T-cell, B-cell, and monocyte quantitations. T-cell quantitation was performed by incubating Ficoll-Hypaque-separated mononuclear cells with sheep erythrocytes and counting the number of lymphocytes with at least three adherent erythrocytes (9). Incubation to remove serum factors that might interfere with T-cell quantitation was not done because E-rosette counts in untreated patients did not differ significantly from the range seen in normal subjects with this method. B cells were quantitated using direct immunofluorescence staining of surface immunoglobulins (10). Monocytes were stained with the cytoplasmic esterase technique (11).

Cell separation techniques. Spleen tissue was placed in McCoy's medium immediately after surgical removal. The fresh tissue was minced, passed through wire mesh, and then through fine gauze. The preparation was washed and pelleted, resuspended in McCoy's medium, and layered on Ficoll-

TABLE I

Lymphocyte Transformation and Interferon Production to Herpes Viral Antigens in Untreated Lymphoma Patients

\begin{tabular}{|c|c|c|c|c|c|c|c|}
\hline \multirow[b]{2}{*}{ Pathologic diagnosis } & \multicolumn{3}{|c|}{$\begin{array}{l}\text { Percent of patients with } \geq 3.0 \\
\text { lymphocyte transformation }\end{array}$} & \multicolumn{4}{|c|}{$\begin{array}{l}\text { Percent of patients with interferon } \\
\text { production } \geq 1.0 \log \text { units }\end{array}$} \\
\hline & $\mathrm{VZ}$ & HSV & CMV & VZ & HSV & CMV & \\
\hline & $(n)$ & (n) & $(n)$ & (n) & (n) & & (n) \\
\hline Hodgkin's disease & $46(63)$ & $91(35)$ & $63(19)$ & $79(63)$ & $97(35)$ & 77 & (17) \\
\hline Stage IA, IB, IIA, IIB, IIIA & $53(55)$ & $90(30)$ & 71 (19) & $78(55)$ & $97(30)$ & 88 & (17) \\
\hline Stage IIIB, IVA, IVB & $\begin{array}{ll}0 & (8)\end{array}$ & $100 \quad(5)$ & $0 \quad(2)$ & $75 \quad(8)$ & 100 & 0 & (2) \\
\hline Non-Hodgkin's lymphoma & $58(65)$ & $80(50)$ & $66(44)$ & $83(65)$ & $94(50)$ & 84 & (44) \\
\hline Stage IA, IB, IIA, IIB, IIIA & $65(40)$ & $86(29)$ & $83(24)$ & $90(40)$ & $100(29)$ & 88 & $(24)$ \\
\hline Stage IIB, IVA, IVB & $48(25)$ & $71(21)$ & $45(20)$ & $72(25)$ & $86(21)$ & 80 & $(20)$ \\
\hline
\end{tabular}


Hypaque or on nylon fiber columns. Nylon fiber columns were used to obtain cell preparations with increased numbers of $\mathrm{T}$ cells; E-rosette depletion of Ficoll-Hypaque-separated cells was done to obtain B-cell-enriched preparations (12). The percentage of $\mathrm{T}$ cells in the column-purified preparations was $84 \pm 2.59 \mathrm{SE}$; E-rosette-depleted cells had $<10 \%$ E-rosetting cells. The peripheral blood and spleen Ficoll-Hypaqueseparated cell preparations contained $53 \pm 5.42$ and $45 \pm 6.97 \%$ SE E-rosetting cells, respectively; B-cell counts were $24 \pm 2.99$ and $36 \pm 3.30 \mathrm{SE}$; monocyte counts were $12 \pm 3.33$ and $16 \pm 2.56 \mathrm{SE}$.

Antibody measurement. Antibodies to HSV and CMV were measured with a standard complement fixation assay (13). VZ antibody was measured with an indirect fluorescence method previously described (7). All sera collected from an individual patient were tested at the same time.

Viral cultures. For isolation of $\mathrm{HSV}$ and CMV, throat gargle material or urine obtained at each follow-up interval was mixed with gentamicin and amphotericin, inoculated into triplicate human foreskin fibroblast culture tubes, and examined twice weekly for cytopathic effect over a 4-wk period. HSV isolates were identified by direct fluorescence with specific antisera; CMV isolates were identified by cytopathic effect. Although the rate of viral shedding was low in lymphoma patients, the cardiac transplant recipients being monitored at the same time had high rates of viral shedding in our culture system.

\section{RESULTS}

\section{Cellular immunity in lymphoma patients before treatment}

The data confirm our observation that untreated lymphoma patients have a deficiency in lymphocyte transformation to $\mathrm{VZ}$ antigen (7). Fewer patients responded to $\mathrm{VZ}$ antigen than to $\mathrm{HSV}$ or CMV antigens in both the Hodgkin's and non-Hodgkin's lymphoma groups (Table I). Among Hodgkin's patients, the extent of the disease at diagnosis correlated with diminished lymphocyte transformation to $\mathrm{VZ}$ antigen. None of the patients with stage IIIB, IVA, or IVB had detectable lymphocyte transformation to $\mathrm{VZ}$ antigen, although the responses were more than threefold in $53 \%$ of those with stage IA, IB, IIA, IIB, and IIIA disease $\left(\chi^{2}\right.$, $P<0.05$ ). The mean lymphocyte transformation to PHA antigen was also lower in Hodgkin's patients with stage IIIB-IVB disease (mean $=22.8 \pm 4.4 \mathrm{SE}$ ) compared with those with stage IA-IIIA disease (mean $=33.3 \pm 5.32 \mathrm{SE}$ ), but was equivalent in patients with non-Hodgkin's lymphoma, stage IA-IIIA (mean $=39.7 \pm 4.4 \mathrm{SE}$ ), and stage IIIB-IVB (mean $=38.1$ $\pm 5.32 \mathrm{SE}$ ). All of the viral antigens stimulated in vitro interferon production in most untreated patients, including those with extensive disease (Table I).

The suppression of lymphocyte transformation in untreated patients could not be attributed to a serum factor because responses to VZ, HSV, and PHA antigens were equivalent whether cells were incubated in the patients serum or in pooled normal serum among 12 patients tested (14). Increased prostaglandin synthesis has been implicated in the suppression of in vitro cellular responses in lymphoma patients (15). Cells from four patients were incubated with indomethacin, a prostaglandin inhibitor, in concentrations ranging from 0.05-1.0 $\mu \mathrm{g} / \mathrm{ml}$, with no effect upon lymphocyte transformation to $\mathrm{VZ}$ or PHA.

\section{The effect of splenectomy on cellular immunity in untreated patients}

Because some epidemiologic studies suggest that splenectomy increases the risk of herpes zoster infection in lymphoma patients (1), cellular immunity was evaluated in 20 patients before and 5-7 d after splenectomy. 10 of 20 patients tested before splenectomy had lymphocyte transformation $\geq 3.0$ to $\mathrm{VZ}$ antigen. Of these, only five responded to $\mathrm{VZ}$ antigen after splenectomy. All patients tested before splenectomy had interferon production to $\mathrm{VZ}$ antigen compared with 14 of $20(70 \%)$ after splenectomy. Splenectomy was associated with suppression of lymphocyte transformation to HSV in 3 of $10 \mathrm{HSV}$ seropositive patients. Although these changes in cellular immune response may be, in part, the result of the postoperative status of the patients, lymphocyte transformation to PHA was intact in 16 of 19 patients after splenectomy.

The mean VZ lymphocyte transformation in mononuclear cell cultures prepared from splenic tissue was $5.6 \pm 0.98 \mathrm{SE}$ compared with a mean peripheral blood response of $2.5 \pm 0.82 \mathrm{SE}$ in 14 patients tested $(P<0.05$, $t$ test), despite the fact that the numbers of E-rosetting cells were equivalent $(60 \pm 3.43 ; 64 \pm 3.19)$. 8 of 11 patients whose peripheral blood mononuclear cells showed no response to $\mathrm{VZ}$ antigen had lymphocyte transformation to $\mathrm{VZ}$ antigen in cultures of splenic cells $\left(\chi^{2}, P<0.05\right)$, suggesting that the spleen may be a source of VZ-reactive cells in patients with none detectable in the circulating lymphocyte pool. Using column-purified $T$ cells recombined with $B$ cells and monocytes, lymphocyte transformation was studied in 11 patients. The splenic cell response was optimal with 75-83\% E-rosetting cells (mean lymphocyte transformation to $\mathrm{VZ}=5.5 \pm 0.72 \mathrm{SE}$ ) and was eliminated by the depletion of $\mathrm{T}$ cells to $<35 \%$. Although there is some evidence that lymphoma patients have circulating suppressor cells in adherent cell subpopulations (15), the response of splenic T cells was not suppressed by recombination with peripheral blood-derived B-cell monocyte preparations in five of seven patients who had no VZ lymphocyte transformation in peripheral blood mononuclear cell cultures. Conversely, the peripheral blood T-cell response was not restored in three seropositive patients whose column-purified peripheral blood $\mathrm{T}$ cells were cultured with spleenderived B-cell monocyte preparations. The enrichment of peripheral blood mononuclear cell cultures for $\mathrm{T}$ 
cells so that cultures contained $73-84 \%$ E-rosetting cells did not result in detectable transformation in five patients studied.

\section{Correlation of the effect of therapy on cellular} and humoral immunity to VZ, HSV, and CMV with the occurrence of clinical and laboratory evidence of infection

VZ. 13 cases of herpes zoster occurred during the period of the prospective study. 8 of 40 patients with Hodgkin's disease had herpes zoster (20\%) compared with 5 of 46 non-Hodgkin's lymphoma patients (11\%). Of the 13 cases, 8 occurred in patients treated with both radiation and chemotherapy (19\%), including 6 of 31 Hodgkin's and 2 of 11 non-Hodgkin's patients. All of the cases of herpes zoster in patients given both radiation and chemotherapy were seen in those given maximum amounts of radiation, i.e., total nodal radiation for Hodgkin's disease or mantle/whole abdomen/pelvic radiation for non-Hodgkin's lymphoma. In this group, the incidence of herpes zoster was 8 of $29(27.6 \%)$. 4 patients given radiation only had herpes zoster (16\%), including 2 of 9 Hodgkin's and 2 of 16 non-Hodgkin's patients. One case occurred among 19 patients with non-Hodgkin's lymphoma given chemotherapy only $(5.2 \%)$.
This distribution of episodes of $\mathrm{VZ}$ reactivation among the three treatment groups correlated with the number of patients having no lymphocyte transformation response to $\mathrm{VZ}$ antigen at each test interval, and with the duration of suppression of the response in each treatment group (Fig. 1). The mean lymphocyte transformation to $\mathrm{VZ}$ antigen was below the normal range for the first 16 mo of treatment in patients who received radiation and chemotherapy or radiation therapy only. However, a significant number of patients treated with radiation only showed lymphocyte transformation responses $\geq 3.0$ to $\mathrm{VZ}$ antigen by $12-16 \mathrm{mo}(59 \%)$ compared with those given radiation and chemotherapy (Fig. 1). At each interval, significantly fewer patients in the radiation and chemotherapy group had a lymphocyte transformation $\geq 3.0$ to $\mathrm{VZ}$ antigen when compared with the patients given either single modality therapy $\left(\chi^{2}, P<0.05\right.$ for each comparison). The prolonged suppression of lymphocyte transformation and the occurrence of episodes of herpes zoster were seen in patients with less extensive disease, with stage IA-IIB, who were treated with maximum amounts of radiation and chemotherapy, as well as in patients with stage IIIA-IVB disease (Fig. 2). Patients given radiation only with an equivalent extent of disease had better preservation of lymphocyte transformation and fewer episodes of herpes zoster (Fig. 2). Although the mean

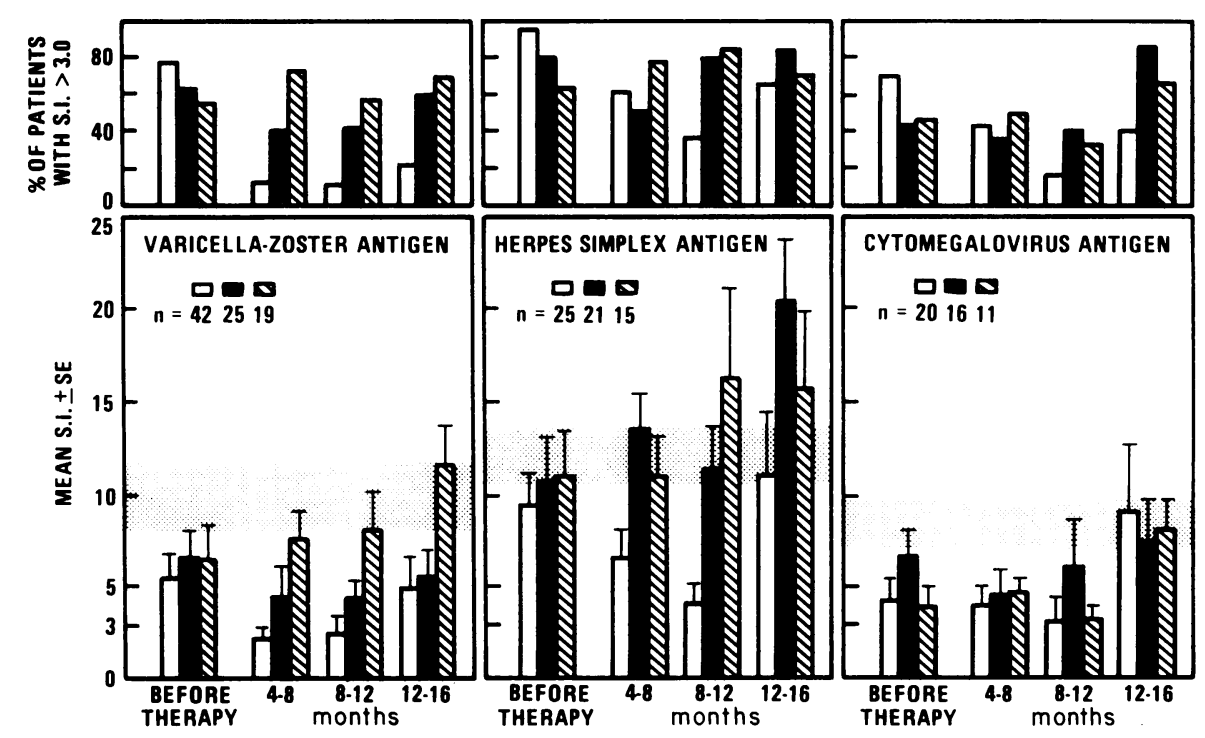

FIGURE 1 The effect of therapy upon lymphocyte transformation to VZ, HSV, and CMV antigens in seropositive patients. The lower portion of the figure shows the mean $\mathrm{SI} \pm \mathrm{SE}$, I, to each of the viral antigens in relation to the treatment given. The SI is a ratio of counts per minute in antigen-stimulated cultures to counts per minute in the appropriate control cultures. The treatment groups include radiation plus chemotherapy $(\square)$, radiation only $(\square)$, and chemotherapy only $(\mathbb{\otimes})$. The numbers of seropositive patients tested with each antigen in each treatment group is given as " $n$." The horizontal shaded area (अ) indicates the mean SI \pm SE seen in normal seropositive subjects tested with each antigen. The upper portion of the figure shows the percentage of patients in each treatment group who had detectable lymphocyte transformation to the viral antigens at each test interval. 


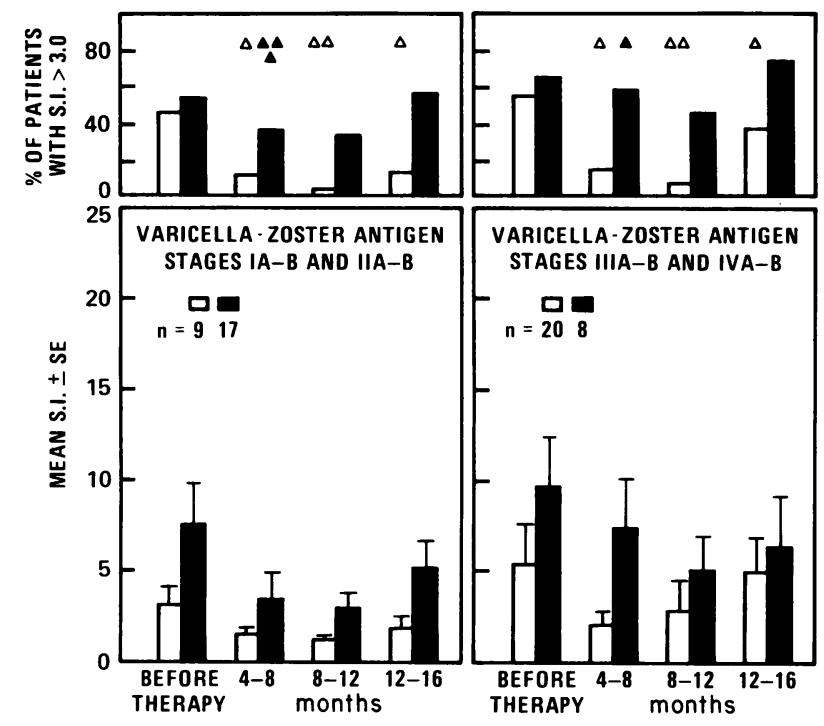

Figure 2 The effect of therapy upon lymphocyte transformation to $\mathrm{VZ}$ antigen related to the stage of disease and therapy given. The lower portion of the figure shows the mean $\mathrm{SI} \pm \mathrm{SE}(\boldsymbol{I})$ to $\mathrm{VZ}$ antigen in relation to the treatment given. The SI is a ratio of counts per minute in the control cultures. The treatment groups include radiation plus chemotherapy $(\square)$ and radiation only $(\square)$. The number of patients tested in each treatment group is given as "n." The upper portion of the figure shows the percentage of patients in each treatment group who had detectable lymphocyte transformation to the antigen at each test interval and the occurrence of cases of herpes zoster, indicated by $\boldsymbol{\Delta}$ for patients given radiation and $\Delta$ for those given radiation and chemotherapy. The right-hand portion of the figure provides these data in subjects with stage IA, IB, IIA, or IIB disease; the lefthand portion shows these data in subjects with stage IIIA, IIIB, IVA, or IVB disease.

interferon production to $\mathrm{VZ}$ antigen was below the normal range for all three treatment groups during the period of study, 79-92\% of the patients in each group had interferon production $\geq 1.0 \log$ units at each test interval (Fig. 3).

As shown in Fig. 4, the cases of herpes zoster in patients treated with radiation only were observed when $<40 \%$ of the patients had lymphocyte transformation to VZ antigen; no cases occurred at 12-16 mo after diagnosis when 15 of 25 patients had recovered lymphocyte transformation to $\mathrm{VZ}$ antigen. In contrast, at 12-16 mo, only 9 of 42 patients given radiation and chemotherapy responded to $\mathrm{VZ}$ antigen, and episodes of herpes zoster continued to occur throughout this later period of follow-up.

These data showing the pattern of suppression of lymphocyte transformation to $\mathrm{VZ}$ antigen during the initial treatment of lymphoma also correlate with the epidemiology of herpes zoster in the lymphoma patients treated at Stanford from January 1973 to December 1978 (Fig. 4). During this period, 42 episodes of herpes zoster were diagnosed in patients given radiation therapy only. An analysis of the percentage of cases occurring at each interval after diagnosis showed that $43 \%$ had occurred within 4-8 mo and that $75 \%$ had occurred by $12-16$ mo after diagnosis. The distribution of 100 episodes in patients given both radiation and chemotherapy differed in that substantial numbers of cases were seen until 20-24 mo after diagnosis; $75 \%$ of cases had not occurred until 24-28 mo after diagnosis (Fig. 4).

The loss of lymphocyte transformation to $\mathrm{VZ}$ antigen preceded the occurrence of herpes zoster in all 13 patients who developed herpes zoster during the prospective study. Declining VZ antibody levels were not detected in these patients and their VZ antibody titers were equivalent to those in patients who, matched by disease, age, and therapy, did not develop clinical herpes zoster infection (Table II). VZ antibody titers did not decline during treatment in patients

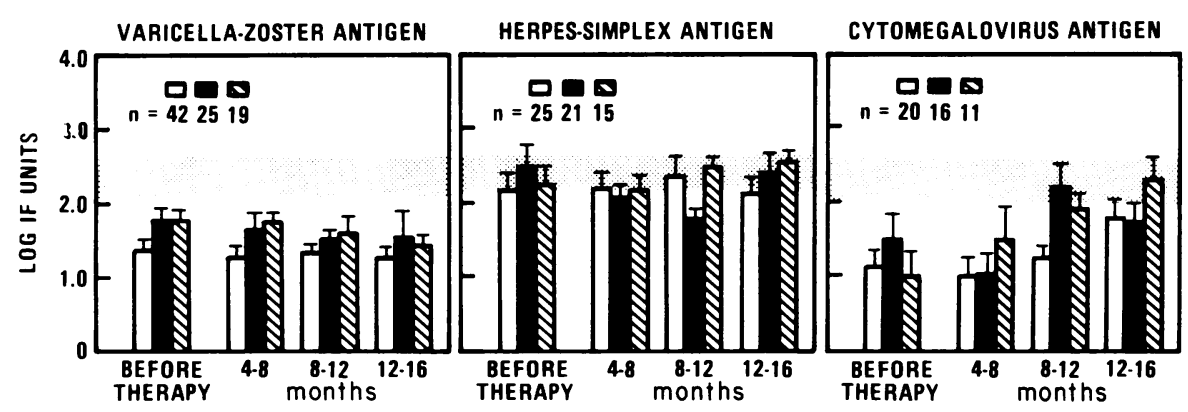

Figure 3 The effect of therapy upon interferon production to VZ, HSV, and CMV antigens in seropositive patients. The mean $\log _{10}$ interferon (IF) production $\pm S E$ (I) to each of the viral antigens is shown for each treatment group during the first $16 \mathrm{mo}$ after diagnosis. The data for interferon production are titers expressed as the $\log _{10}$ of the dilution, giving $50 \%$ inhibition of the cytopathic effect of vesicular stomatitis virus. The treatment groups include radiation plus chemotherapy $(\square)$, radiation only $(\square)$, and chemotherapy only $(\boldsymbol{\nabla})$. The number of seropositive patients tested with each antigen in each treatment group is given as " $n$." The horizontal shaded area (ख) indicates the mean $\log _{10}$ interferon production $\pm S E$ seen in normal seropositive subjects tested with each antigen. 


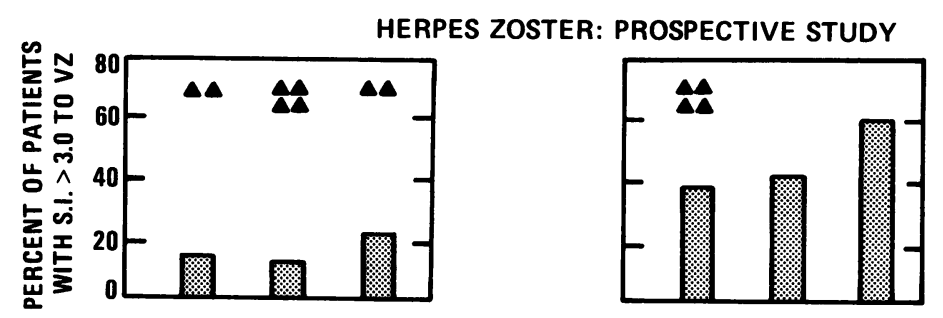

HERPES ZOSTER: 1973-1978

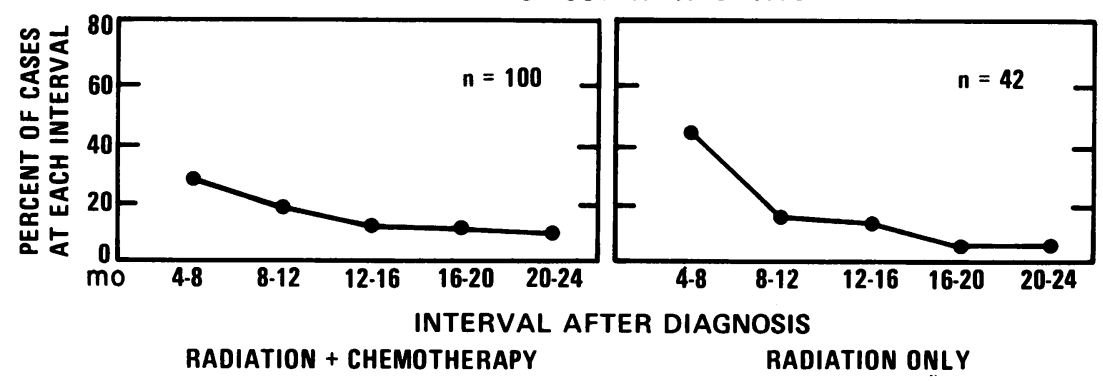

FIGURE 4 The occurrence of herpes zoster during the treatment of lymphoma among patients treated at Stanford University Medical Center from January 1973 to December 1978. The upper portion of the figure shows the occurrence of cases of herpes zoster in the prospective study, indicated by $\boldsymbol{\Delta}$, among patients given radiation plus chemotherapy and those given radiation only in relation to the percentage of patients with detectable lymphocyte transformation to $\mathrm{VZ}$ antigen at each follow-up interval. The lower portion of the figure shows the epidemiology of herpes zoster with the initial therapy of lymphoma among patients treated between 1973 and 1978. The dark circles (O) indicate the percentage of the total number of cases in each treatment group that occurred at each interval after diagnosis. The number of cases analyzed in each treatment group is given as "n."

given maximum radiation and chemotherapy, which was the group at greatest risk of developing herpes zoster (Table II).

$H S V$. Despite therapy, clinical HSV infection was mild in 60 of $61 \mathrm{HSV}$ seropositive patients. $62 \%$ of the patients had no clinical infection, $26.2 \%$ had one or two lesions with no change in frequency or severity compared with pretreatment infection, and $6.6 \%$ had four to six lesions with no increased frequency or severity. Two patients experienced an increase in severity or frequency of lesions. These findings correlated with the better preservation of cell-mediated immune responses to $\mathrm{HSV}$ antigen during treatment. The mean lymphocyte transformation to $\mathrm{HSV}$ antigen remained at the normal range in patients given radiation only or chemotherapy only throughout the follow-up period (Fig. 1). Patients given radiation and chemotherapy had mean levels of transformation to HSV antigen significantly below those in the single modality treatment groups at the 4-8- and 8-12-mo intervals

TABLE II

Geometric Mean VZ Antibody Titers

\begin{tabular}{|c|c|c|c|}
\hline & $\begin{array}{l}\text { Patients given } \\
\text { maximum radiation } \\
\text { plus chemotherapy } \\
\qquad(n=21)^{*}\end{array}$ & $\begin{array}{c}\text { Patients } \\
\text { who developed } \\
\text { herpes zoster } \\
(n=13)\end{array}$ & $\begin{array}{l}\text { Matched patients } \\
\text { with no } \\
\text { herpes zoster } \\
(n=13) !\end{array}$ \\
\hline Before treatment & $1: 151$ & $1: 115$ & $1: 186$ \\
\hline \multicolumn{4}{|l|}{ During treatment } \\
\hline 4-8 mo & $1: 309$ & & \\
\hline $8-12 \mathrm{mo}$ & $1: 166$ & $1: 218 \S$ & $1: 275^{\prime \prime}$ \\
\hline $12-16 \mathrm{mo}$ & $1: 151$ & & \\
\hline
\end{tabular}


$(P<0.05, t$ test $)$ but not at 12-16 mo. Except in the radiation and chemotherapy group at the 8-12-mo interval, the percentage of patients with lymphocyte transformation $\geq 3.0$ to HSV antigen was consistently $>50 \%$. Interferon production to $\mathrm{HSV}$ antigen remained in the normal range for all three groups (Fig. 3).

Asymptomatic HSV shedding was detected in five patients. Four of the five episodes occurred in patients given both radiation and chemotherapy ( 4 of $25 ; 16 \%$ ) within 12 mo after diagnosis, when HSV lymphocyte transformation was diminished in this group. One patient had received radiation only ( 1 of $24 ; 4.8 \%$ ). None of these patients had lymphocyte transformation to HSV antigen at the time virus shedding was documented; four of the five had responses $>3.0$ at the next test interval and were no longer shedding virus. A sixth patient had seroconversion to HSV indicating primary HSV infection, and acquired lymphocyte transformation to HSV antigen without clinically apparent infection. A seventh patient with diffuse histiocytic lymphoma, stage IVB, with brain involvement, who had received 3,500 rads whole brain irradiation and intrathecal methotrexate, developed fatal HSV encephalitis. This patient had no lymphocyte transformation to HSV antigen before the onset of the infection.

There were no significant differences in HSV antibody titers among patients receiving both radiation and chemotherapy when compared with those given radiation or chemotherapy only (Table III).

CMV. 47 patients had antibody to CMV at the time of diagnosis. No symptomatic illness attributable to CMV was identified in any of these patients during the prospective study. None of the 39 patients without CMV antibody at diagnosis showed seroconversion during the study period.

The mean lymphocyte transformation to CMV antigen was below the normal range in all of the treatment groups at 4-8 mo after diagnosis, and remained low in the combined therapy and chemotherapy-only groups at 8-12 mo (Fig. 1). By 12-16 mo, the mean lymphocyte transformation responses and the number of patients with greater than threefold response to CMV antigen were not significantly different among the three treatment groups. Mean interferon production to CMV antigen was initially diminished in patients given radiation and chemotherapy or radiation only, but was not significantly different from the normal range by $12-16$ mo in any of the treatment groups (Fig. 3).

Asymptomatic CMV shedding was detected in one patient receiving both radiation and chemotherapy ( 1 of $20 ; 5 \%$ ). Based on a fourfold rise in antibody titer, serologic evidence of CMV reactivation was noted in four patients. One of these patients received radiation only ( 1 of $16,6.3 \%$ incidence) and three were treated with radiation and chemotherapy (3 of 20, $15 \%$ incidence). All of the patients with CMV reactivation had lymphocyte transformation $<3.0$ to $\mathrm{CMV}$ antigen before the occurrence of the fourfold increase in antibody titer or of viral excretion.

PHA transformation and quantitation of $T$ cells. Patients given radiation and chemotherapy had significantly diminished lymphocyte transformation to PHA at $4-8$ mo $(P<0.05, t$ test $)$ compared with those given single modality therapy (Fig. 5). The effect of therapy on PHA response appeared to be independent of the extent of disease. Among patients given radiation and chemotherapy, the mean PHA SI declined to $13 \pm 3.81 \mathrm{SE}$ in those with stage IA-IIB disease and to $14.5 \pm 3.17 \mathrm{SE}$ in those with stage IIIA-IVB disease during the first months of treatment, and increased to $43 \pm 14.02$ and $43 \pm 16.64$, respectively, by $12-16$ mo.

The quantitation of $T$ cells by $E$ rosetting showed suppression in all patient groups at each interval after

TABLE III

Geometric Mean HSV and CMV Complement Fixation Antibody Titers during Therapy

\begin{tabular}{|c|c|c|c|c|c|c|}
\hline & & & \multicolumn{4}{|c|}{ Therapy } \\
\hline & & & Before & $\begin{array}{l}4-8 \\
\text { mo }\end{array}$ & $\begin{array}{c}8-12 \\
\text { mo }\end{array}$ & $\begin{array}{c}12-16 \\
\text { mo }\end{array}$ \\
\hline & & $n$ & & & & \\
\hline \multirow[t]{3}{*}{ HSV } & Radiation plus chemotherapy & 25 & $1: 43$ & $1: 45$ & $1: 58$ & $1: 69$ \\
\hline & Radiation only & 21 & $1: 44$ & $1: 68$ & $1: 65$ & $1: 69$ \\
\hline & Chemotherapy only & 15 & $1: 35$ & $1: 29$ & $1: 40$ & $1: 29$ \\
\hline \multirow[t]{3}{*}{ CMV } & Radiation plus chemotherapy & 20 & $1: 31$ & $1: 59$ & *1:123 & $1: 93$ \\
\hline & Radiation only & 16 & $1: 39$ & $1: 64$ & $\$ 1: 91$ & $1: 83$ \\
\hline & Chemotherapy only & 11 & $1: 50$ & $1: 54$ & $1: 81$ & $1: 110$ \\
\hline
\end{tabular}

* Three patients with fourfold rise.

‡ One patient with fourfold rise. 

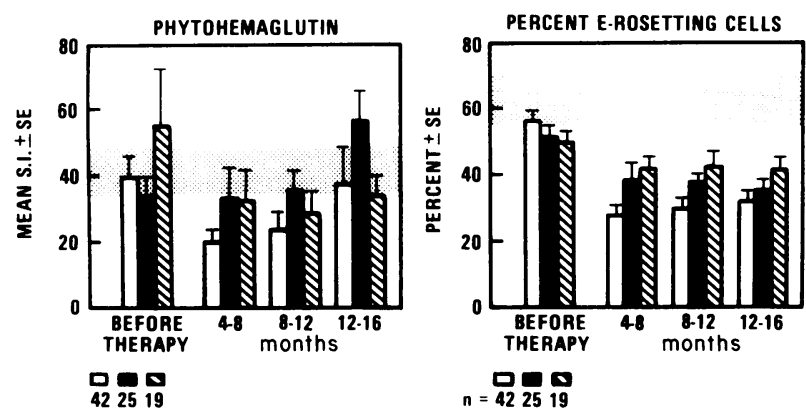

Figure 5 The effect of therapy upon lymphocyte transformation to PHA and upon the percentage of $\mathrm{E}$ rosette-forming cells in peripheral blood. The portion of the figure on the left shows the mean $\mathrm{SI} \pm \mathrm{SE}$ (I) to PHA in relation to the treatment given. The $\mathrm{SI}$ is a ratio of counts per minute in PHA-stimulated cultures to counts per minute in control cultures. The right portion of the figure shows the mean percentage of $E$ rosetteforming cells $\pm \mathrm{SE}(\boldsymbol{I})$ in relation to the treatment given. The treatment groups include radiation plus chemotherapy ( $\square)$, radiation only $(\square)$, and chemotherapy only $(\$)$. The shaded areas $(\circledast)$ in each portion of the figure represent the mean $\pm \mathrm{SE}$ for these assays in normal subjects. The number of patients tested in each treatment group is given as "n."

diagnosis. The trend toward recovery of lymphocyte transformation to viral antigens and PHA occurred despite no significant increase in the percentage of E rosette-forming cells during the follow-up period (Figs. 1 and 4).

Evaluation of cell-mediated immunity in lymphoma patients with acute zoster. 25 patients with lymphoma and herpes zoster were tested during the acute infection. As shown in Fig. 6, lymphoma patients recovered lymphocyte transformation to $\mathrm{VZ}$ antigen with the occurrence of herpes zoster, mean $1.8 \pm 0.85 \mathrm{SD}$ at $<1$ wk compared with $5.7 \pm 3.03 \mathrm{SD}$ at $2-4$ wk $(P=0.001)$, although the increase was less than that seen in normal subjects with acute zoster. The increase in lymphocyte transformation did not occur until 2-4 wk after the onset of clinical infection in lymphoma patients, compared with 1-2 wk in normal subjects. The levels of in vitro interferon production to $\mathrm{VZ}$ antigen were higher with recovery from acute infection, but this response was also diminished when compared with normal subjects. PHA transformation levels were not significantly different at the time of recovery from infection (mean $=19.2 \pm 5.77$ ) compared with the onset $($ mean $=19.9 \pm 5.09 \mathrm{SE})$. Five of seven patients who were HSV seropositive also showed an increase in lymphocyte transformation to HSV antigen to $\geq 3.0$ by $2-4 \mathrm{wk}$, and 5 of $10 \mathrm{CMV}$ seropositive patients recovered lymphocyte transformation to CMV. The recovery of VZ lymphocyte transformation occurred despite the fact that the percentage of $\mathrm{E}$ rosette-forming cells was $<50 \%$ at $1-2$ and $2-4$ wk after onset in all patients (mean at $1 \mathrm{wk}=24.2 \pm 6.08 \mathrm{SE} ; 1-2 \mathrm{wk}$ $=30.16 \pm 6.98 ; 2-4 \mathrm{wk}=39.6 \pm 3.64 \mathrm{SE})$.
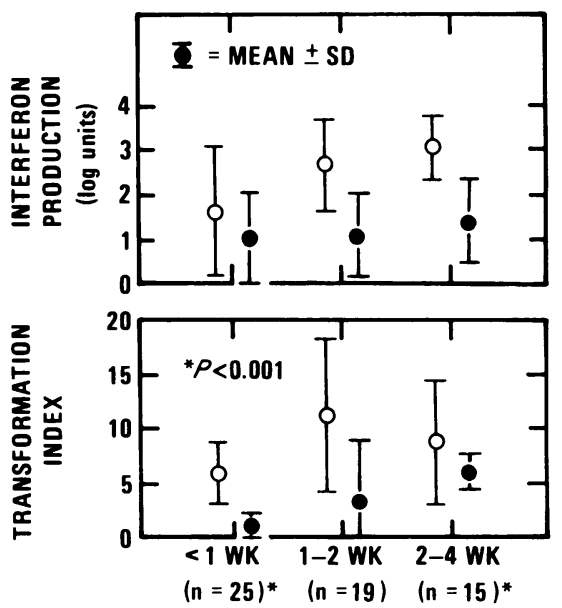

INTERVAL AFTER ONSET OF HERPES ZOSTER

Figure 6 Cellular immune responses to $\mathrm{VZ}$ antigen in normal subjects and lymphoma patients with acute herpes zoster infection. The upper portion of the figure shows mean $\log _{10}$ interferon production to $\mathrm{VZ}$ antigen $\pm \mathrm{SD}$ in patients with lymphoma and acute herpes zoster (O), compared with the responses seen in normal subjects with acute herpes zoster (O), at intervals after the onset of infection. The data for interferon production are titers expressed as the $\log _{10}$ of the dilution, giving $50 \%$ inhibition of the cytopathic effect of vesicular stomatitis virus. The lower portion of the figure shows the mean SI to $\mathrm{VZ}$ antigen $\pm \mathrm{SD}, \Phi$, in lymphoma patients and in normal subjects with herpes zoster. The data in normal subjects are based on the testing of 42 individuals. The $\mathrm{SI}$ is a ratio of counts per minute in antigen-stimulated cultures to counts per minute in control cultures.

\section{DISCUSSION}

In this prospective study, lymphoma patients treated with both radiation and chemotherapy were more susceptible to the reactivation of latent VZ, HSV, and CMV than patients given radiation or chemotherapy only. The suppression of lymphocyte transformation to herpes viral antigens in this patient group correlated with the increased frequency of viral reactivation. Diminished lymphocyte transformation to the specific viral antigen preceded the episodes of viral reactivation observed in individual patients, but the failure to respond did not predict that reactivation would definitely occur. In the individual patient, the suppression of lymphocyte transformation appears to be a necessary but not a sufficient condition for the reactivation of latent infection. The incidence of reactivation among patients at risk, defined as those with lymphocyte transformation $<3.0$, at each follow-up interval for each of the viruses averaged $10 \%$ with a range of $6-14 \%$. The correlation between the failure to exhibit an in vitro lymphocyte response to the viral antigen and the reactivation of the virus may become more precise when more well-defined viral antigens 
can be used in the assay, or when other deficiencies associated with diminished lymphocyte transformation are identified.

Herpes zoster infection is the most carefully studied form of herpes virus reactivation among patients with lymphoma (1-3). The prolonged susceptibility to herpes zoster observed in patients treated with both radiation and chemotherapy may be accounted for by the prolonged suppression of lymphocyte transformation to $\mathrm{VZ}$ antigen among most patients in this treatment group. Ruckdeschel et al. (16) also noted suppression of lymphocyte transformation to $\mathrm{VZ}$ antigen in patients given combined therapy. Schimpff et al. (2) found that most cases of herpes zoster in patients treated with radiation occur during or shortly after treatment, as was noted in the present study. The interval of increased susceptibility to herpes zoster in patients given radiation only corresponds to the period of maximum suppression of lymphocyte transformation to VZ antigen in this group. Non-Hodgkin's lymphoma patients have fewer episodes of herpes zoster than patients with Hodgkin's disease in most epidemiologic studies $(1,3)$. In our experience, non-Hodgkin's lymphoma patients were more often treated with single modality therapy that decreased cellular immunity to $\mathrm{VZ}$ antigen in fewer patients and for a shorter period of time. Among non-Hodgkin's patients treated with both radiation and chemotherapy, the incidence of herpes zoster was equivalent to that in Hodgkin's patients given combined therapy.

The association of the lymphocyte transformation response with the host's ability to restrict viral reactivation is also suggested by the increase in VZ lymphocyte transformation that accompanied uncomplicated recovery from herpes zoster infection in lymphoma patients. The kinetics of the recovery of the response was somewhat delayed compared with normal subjects with herpes zoster, but all of these patients did develop VZ lymphocyte transformation within 2-4 wk. Patel et al. (17) have made similar observations in children with malignancy and herpes zoster. Conversely, prolonged herpes zoster has been reported in immunocompromised patients whose chemotherapy was continued and who failed to recover lymphocyte transformation with acute infection (18).

Although cases of severe HSV infection in patients with lymphoma are well documented $(5,7,19)$, and one patient in this study had fatal HSV encephalitis, this prospective study suggests that most patients with lymphoma either have no HSV reactivation or have uncomplicated infection. Aston et al. (5) found HSV shedding in 3 of $54(5.5 \%)$ patients with myeloproliferative and lymphoproliferative malignancy, which is similar to the incidence reported in normal populations (20). Within our patient population, the suppression of lymphocyte transformation to $\mathrm{HSV}$ antigen identified patients given both radiation and chemotherapy as being the group at highest risk of $\mathrm{HSV}$ reactivation during the first 12 mo of treatment.

The shorter duration of suppression of cellular immunity to HSV antigen compared with VZ antigen observed in lymphoma patients was also seen in cardiac transplant recipients $(21)$. One hypothesis concerning the recovery of cellular immunity is that viral reactivation occurs and "reimmunizes" the patient. The data in the cardiac transplant recipients supported this explanation for the earlier recovery of the HSV response because $83 \%$ of the patients had evidence of $\mathrm{HSV}$ reactivation shortly after transplantation. The lymphoma patients recovered cellular immune responses to HSV antigen without such a high reactivation rate, although low levels of viral replication may have occurred that were not detectable as clinical infection or as asymptomatic shedding with our monitoring regimen. Although most patients recovered CMV responses without evidence of reactivation, the smaller numbers of CMV seropositive patients limit the interpretation of these data. Of those patients who recovered VZ responses, however, most did not have clinically recognizable herpes zoster.

That reactivation of herpes viruses during the treatment of lymphoma was not associated with detectable suppression of antibody to herpes viruses is consistent with our studies of these infections in cardiac transplant recipients (21). Aston et al. (5) found no differences in HSV-neutralizing antibody titers in patients with malignancy who had HSV lesions or asymptomatic shedding, and those with no evidence of reactivation. In a prospective study of renal transplant recipients, Luby et al. (22) observed that VZ antibody titers were equivalent between patients who developed herpes zoster and those who did not.

Diminished interferon production could constitute a second deficiency, contributing to the reactivation of latent infection in lymphoma patients. Interferon production was detectable in almost all patients throughout the follow-up period, although interferon titers to $\mathrm{VZ}$ and CMV antigens were reduced during the periods of highest risk for reactivation. The observation that B-cell numbers begin to increase within a few weeks after radiation therapy is completed may explain the better preservation of in vitro interferon production compared with lymphocyte transformation in lymphoma patients (23).

A differential rate of recovery of transformation to nonspecific mitogens has been observed in treated lymphoma patients $(23,24)$. The variation in the interval preceding the recovery of responses to the herpes viral antigens may reflect a difference in the rate of reproliferation of subpopulations of cells capable of responding to each antigen that does not depend upon the stimulus of viral reactivation. Our data confirm that T-cell numbers remain low for a prolonged period with the 
treatment of lymphoma $(23,24)$, and demonstrate that the recovery of normal numbers of $\mathrm{T}$ cells is not necessary for the recovery of lymphocyte transformation to the viral antigen. The recovery of PHA transformation did not parallel the return of transformation to the specific viral antigens closely enough to predict that viral cellular immunity would be present if PHA transformation was detectable.

In summary, these studies show that untreated lymphoma patients have preexisting deficiencies in cellular immunity to herpes viruses, particularly to VZ. Splenectomy may pontentiate these deficiencies by eliminating a source of antigen-responsive cells. However, the duration of the suppression of viral cellular immunity resulting from treatment appears to be of primary importance in predisposing lymphoma patients to the reactivation of latent herpes viral infection.

\section{ACKNOWLEDGMENTS}

We wish to acknowledge the cooperation of Dr. Henry S. Kaplan and Dr. Saul Rosenberg, the staff of the Stanford University Lymphoma Clinic, and the technical assistance of Ms. Linda Umbach, Ms. Barbara Graves, Dr. Margaret Sharp, and Ms. Janet Kahle.

This work was supported by U. S. Public Health Service grant AI 05629 and by a Leukemia Society of America fellowship awarded to Dr. Pollard.

\section{REFERENCES}

1. Goffinet, D. R., E. J. Glatstein, and T. C. Merigan. 1972. Herpes-zoster varicella infections and lymphoma. Ann. Intern. Med. 76: 235-240.

2. Schimpff, S., A. Serpick, B. Stoler, B. Rumack, H. Mellin, J. M. Joseph, and J. Block. 1972. Varicella-zoster infection in patients with cancer. Ann. Intern. Med. 75: 241-254.

3. Dolin, R., R. C. Reichman, M. D. Mazur, and R. J. Whitley. 1978. Herpes zoster-varicella infections in immunosuppressed patients. Ann. Intern. Med. 89: 375-378.

4. Betts, R. F., and J. B. Hanshaw. 1977. Cytomegalovirus in the compromised host. Annu. Rev. Med. 28: 103-110.

5. Aston, D. L., A. Cohen, and M. A. Spindler. 1972. Herpes virus hominis infection in patients with myeloproliferative and lymphoproliferative disorders. Br. J. Med. Educ. 4: 462-465.

6. Haahr, S., L. Rasmussen, and T. C. Merigan. 1976. Lymphocyte transformation and interferon production in human mononuclear cell microcultures for assay of cellular immunity to herpes simplex virus. Infect. Im mun. 14: 47-54.

7. Arvin, A. M., R. B. Pollard, L. E. Rasmussen, and T. C. Merigan. 1978. Selective impairment of lymphocyte reactivity to varicella-zoster virus antigen among untreated patients with lymphoma. J. Infect. Dis. 137: 531-540.

8. Pollard, R. B., K. H. Rand, A. M. Arvin, and T. C. Merigan. 1978. Cell-mediated immunity to cytomegalovirus infection in normal subjects and cardiac transplant patients. J. Infect. Dis. 137: 541-549.
9. Jondal, M., G. Holm, and H. Wigsell. 1972. Surface markers on $\mathrm{T}$ and $\mathrm{B}$ lymphocytes J. Exp. Med. 136: 207-215.

10. Bobrove, A. M., S. Strober, L. A. Herzenberg, and J. D. De Pamphilis. 1974. Identification and quantitation of thymus-derived lymphocytes in human peripheral blood. J. Immunol. 112: 520-527.

11. Yam, L. T., C. Y. Li, and W. M. Crosby. 1971. Cytochemical identification of monocytes and granulocytes. Am. J. Clin. Pathol. 55: 283-290.

12. Rasmussen, L., and T. C. Merigan. 1978. Role of T lymphocytes in cellular immune responses during herpes simplex virus infection in humans. Proc. Natl. Acad. Sci. U. S. A. 75: 3957-3961.

13. Lennette, E. H., J. L. Melnick, and R. L. Magoffine. 1974. Clinical virology: introduction to methods. In Manual of Clinical Microbiology. E. H. Lennette, E. H. Spaulding, and J. P. Truant, editors. American Society for Microbiology, Washington, D. C. 2nd edition. 672.

14. Fuks, A., S. Strober, and H. S. Kaplan. 1976. Interaction between serum factors and T lymphocytes in Hodgkin's disease. N. Engl. J. Med. 295: 1273-1287.

15. Goodwin, J. S., R. P. Messner, A. D. Bankhurst, G. T. Peake, J. H. Saiki, and R. C. Williams. 1977. Prostaglandinproducing suppressor cells in Hodgkin's disease. N. Engl. J. Med. 297: 963-968.

16. Ruckdeschel, J. C., S. C. Schimpff, A. C. Smyth, and M. R. J. R. Mardiney, Jr. 1977. Herpes zoster and impaired cell-associated immunity to the varicella-zoster virus in patients with Hodgkin's disease. Am. J. Med. 62: 77-85.

17. Patel, P. A., S. Yoonessi, O'Malley, A. Freeman, A. Gershon, and P. L. Ogra. 1979. Cell-mediated immunity to varicella-zoster virus infection in subjects with lymphoma or leukemia. J. Pediatr. 94: 223-230.

18. Gallagher, J. G., and T. C. Merigan. 1979. High dose immunosuppressive chemotherapy prolongs herpes zoster. Prolonged herpes zoster associated with immunosuppressive therapy. Ann. Intern. Med. 91: 842-846.

19. Muller, S. A., E. C. Herrman, and R. K. Winklemann. 1972. Herpes simplex infection in hematologic malignancies. Am. J. Med. 52: 102-113.

20. Lindgren, K. M., R. G. Douglas, and R. B. Couch. 1968. Significance of herpes virus hominus in respiratory secretions in man. N. Engl. J. Med. 278: 517-523.

21. Rand, K., L. E. Rasmussen, R. P. Pollard, A. Arvin, and T. C. Merigan. 1977. Cellular immunity and herpes virus infections in cardiac transplant patients. N. Engl. J. Med. 296: $1372-1377$.

22. Luby, J. P., C. Ramirez-Rhonda, S. Rinner, A. Hull, and P. Vergne-Marini. 1977. A longitudinal study of varicellazoster virus infections in renal transplant recipients. $J$. Infect. Dis. 135: 659-663.

23. Fuks, Z., S. Strober, A. M. Bobrove, T. Saszauki, A. McMichael, and H. S. Kaplan. 1976. Long term effects of radiation on $\mathrm{T}$ and $\mathrm{B}$ lymphocytes in peripheral blood of patients with Hodgkin's disease. J. Clin. Invest. 58: 803-814.

24. Stratton, J. A., P. E. Byfield, J. E. Byfield, R. C. Small, J. Benfield, and Y. Pilch. 1975. A comparison of the acute effects of radiation therapy including or excluding the thymus, on the lymphocyte subpopulations of cancer patients. J. Clin. Invest. 56: 88-97. 